\title{
Spontaneous Intra-leiomyoma Hemorrhage during Second Trimester of Pregnancy
}

\author{
Khong Jac Mun, Zalina Nusee, and Riduan Tahar
}

\section{ABSTRACT}

\begin{abstract}
Uterine fibroid affects $\mathbf{0 . 3 - 2 . 6 \%}$ of pregnant women and it is usually asymptomatic during pregnancy [1]. In about $10 \%$ of these patients will have complications such as miscarriage, fetal malpresentation, premature rupture of membranes, placenta abruptio, preterm delivery, abdominal pain due to fibroid torsion or degeneration [2]. Bleeding into the uterine fibroid is extremely rare and patient can present with acute abdomen [11]. Up to date, there were only two cases reported and both occur in postpartum period. We present a case of a pregnant woman with huge uterine fibroid with spontaneous intra-leiomyoma bleeding causing hypovolemic shock at 22 weeks of gestation. Because of failure of conservative management, we performed fibroid resection at 22 weeks of gestation with preservation of the pregnancy.
\end{abstract}

Keywords: Leiomyoma, pregnancy, intraleiomyoma haemorrhage, myomectomy, anemia.
Published Online: December 31, 2020

ISSN: $2593-8339$

DOI: 10.24018 /ejmed.2020.2.6.618

\section{Khong Jac Mun *}

Department of obstetrics and gynecology, International Islamic University, Malaysia.

(e-mail: jayee89@gmail.com)

Zalina Nusee

Department of obstetrics and gynecology, International Islamic

University, Malaysia.

(e-mail: drzalina@iium.edu.my)

Riduan Tahar

Department of obstetrics and gynecology, Hospital Sultan Haji Ahmad Shah Pahang, Malaysia.

*Corresponding Author

\section{INTRODUCTION}

Uterine fibroid(leiomyomas) is a benign smooth muscle tumour of the uterus. The reported prevalence of uterine fibroids in pregnancy varies between 1.6 and 10.7 percent, depending upon the trimester of assessment (first versus second) and the size threshold for reporting presence of a fibroid (e.g., range $\geq 0.5$ to $>3 \mathrm{~cm}$ ) [4]-[8]. Among symptomatic woman, pain is one of the most common complaint and it is usually due to fibroid degeneration. It is commonly seen in women with big fibroids of size more than $5 \mathrm{~cm}$ and usually occurs in late second or early third trimester of pregnancy. The reason being rapid growth of fibroid can result in relative decrease in perfusion, leading to tissue hypoxia, ischemia, and necrosis with release of huge amounts of prostaglandins [9]. Bleeding from fibroid is extremely rare but it can occur especially during pregnancy and just after delivery [12].

\section{CASE REPORT}

A 32 -year -old, G2P0+1, known case of uterine fibroid, presented at 22 weeks period of gestation with 2 days history of worsening lower abdominal pain. The pain was of moderate intensity, crampy in character, aggravated by walking, without any change in bowel movement and no vomiting.

On examination, she was in severe pain (visual analogue scale of 9/10) and appear to be pale. Her blood pressure was $128 / 70 \mathrm{mmHg}$, heart rate 118 beats per minute, temperature was $37{ }^{\circ} \mathrm{C}$, respiratory rate 20 breaths per minutes. Abdominal examination showed a gravid uterus with uterine fundal height of $36 \mathrm{~cm}$, and there was a hard mass palpable at fundus and it was tender to touch.

Sonography showed a huge pedunculated subserosal fibroid at fundus measuring $14 \times 13 \mathrm{~cm}$ and an anterior intramural fibroid measuring $8 \times 9 \mathrm{~cm}$ with no hemoperitineum. There was a single live intrauterine fetus at 21 weeks of gestation. Her haemoglobin level was 7.9 g.dl, white cell count was normal. Liver function test and kidney function test were normal. MRI pelvis (Fig. 1) showed a huge pedunculated subserosal fibroid at the uterine fundus measuring $17.8 \mathrm{~cm}(\mathrm{AP}) \times 24.4 \mathrm{~cm}(\mathrm{~W}) \times 20.7 \mathrm{~cm}$, intramural fibroid at the right side of the uterus is measuring $8.6 \mathrm{~cm}$ (AP $\times 4.8 \mathrm{~cm}(\mathrm{~W}) \times 10.6 \mathrm{~cm}(\mathrm{CC})$. There are multiple smaller intramural fibroids seen within anterior and posterior uterine wall.

The patient was admitted to high dependency ward and managed with bed rest, hydration, and analgesics. She received blood transfusion total 3 unit of packed cells in view of haemoglobin count reducing in trend, and after 5 days of conservative treatment, there was no improvement in the symptoms and haemoglobin count was static despite with blood transfusion. Thus, diagnosis of intra-leiomyoma bleeding was made, and couple was then counselled for surgical intervention, laparotomy myomectomy. Given the size of the uterine fibroid and in anticipation of possibility of 
complication, a midline laparotomy was made. Intraoperative findings noted no hemoperitoneum, multiple uterine fibroid (Fig. 2), included a huge subserosal fibroid size $20 \mathrm{~cm} \times 25$ $\mathrm{cm} \times 16 \mathrm{~cm}$ at fundus with thick pedicles (Fig. 2), three small intramural fibroids, size ranging from $2 \mathrm{~cm} \times 3 \mathrm{~cm}$ located at anterior part of the uterus and one intramural fibroid size $9 \times 6 \times 9 \mathrm{~cm}$, at posterior part of uterus. During manipulation, small areas of subserosal fibroid was punctured, releasing $1.2 \mathrm{~L}$ of old blood. The pedicle was then excised with reconstruction of uterus using suture Ecosorb 1. The other fibroids were not removed in view of bleeding. Estimated blood loss was $2.3 \mathrm{~L}$ and she was transfused with 4unit packed cells post operatively. She received seven days of antibiotic post operatively. Her postoperative stay in hospital remained uneventful and she was discharged on fifth day of surgery.

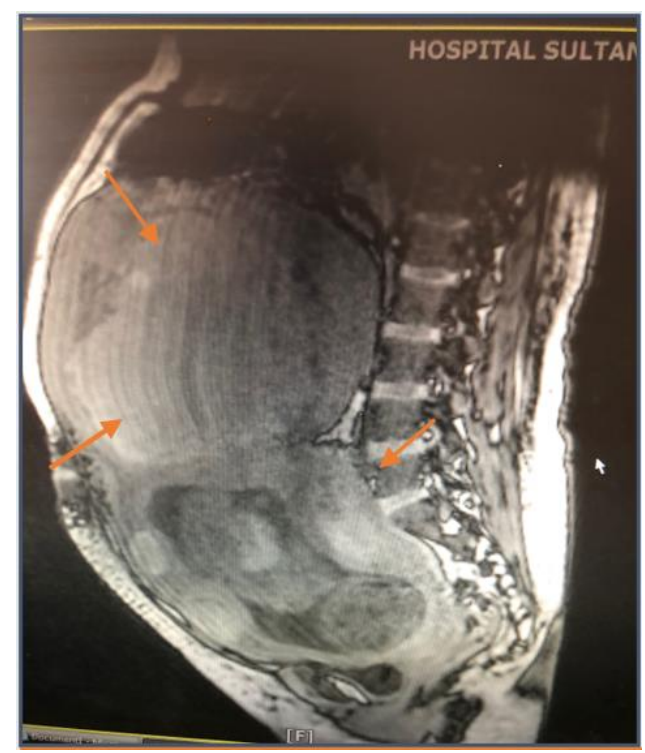

Fig. 1. There is a huge pedunculated subserosal fibroid at the uterine fundus measuring $17.8 \mathrm{~cm}(\mathrm{AP}) \times 24.4 \mathrm{~cm}(\mathrm{~W}) \times 20.7 \mathrm{~cm}(\mathrm{CC})$ intramural fibroid at the right side of the uterus is measuring $8.6 \mathrm{~cm}(\mathrm{AP} \times 4.8 \mathrm{~cm}(\mathrm{~W}) \times$ $10.6 \mathrm{~cm}(\mathrm{CC})$. There are multiple smaller intramural fibroids seen within anterior and posterior uterine wall.

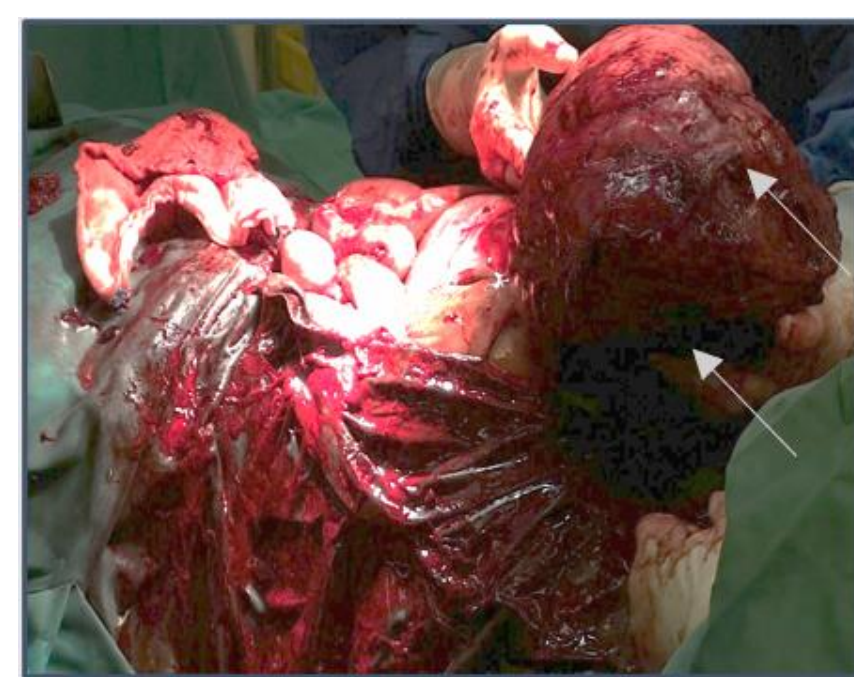

Fig. 2: Intra-operative multiple fibroid uterus and white arrow indicating the subserosal fibroid complicated with intra-leiomyoma haemorrhage.

Pathologically, the mass appears in brownish colour, measuring $19 \times 17.5 \times 19 \mathrm{~cm}$, weight 2.9 kilogram. Serial cut section of the tumour shows a whitish cut surface at the periphery and large area of necrotic tissue at the center. Cut section of separated tissue show dark brownish areas with suggestive of haemorrhage. On microscopic findings, areas of haemorrhage seen in most areas of the infarct.

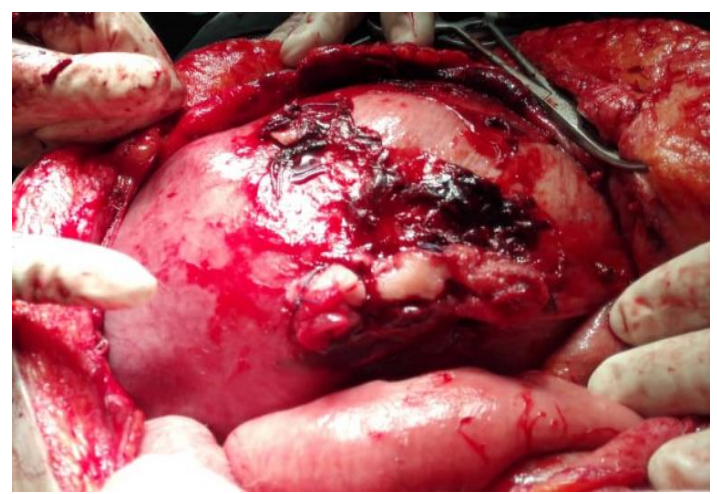

Fig.3. Fundus of uterus after removal of subserosal fibroid.

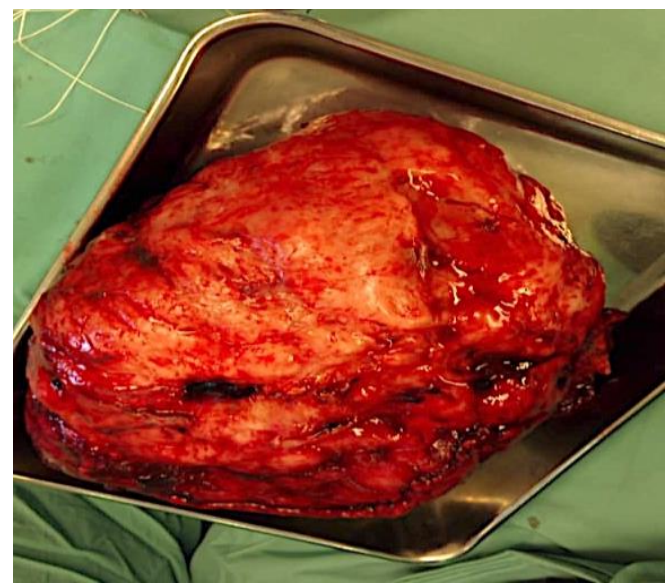

Fig.4. The surgically removed fibroid measuring $19 \times 17.5 \times 19 \mathrm{~cm}$, weight 2.9 kilogram.

The patient was followed up with physical and ultrasound examination every 4 weeks up to 38 weeks and then she had a caesarean section at 39 weeks. The patient delivered a female child of 3.00 kilograms. Intraoperatively, there was multiple fibroid, 2 anterior intramural fibroid largest $6 \times 5 \mathrm{~cm}$, which were kept untouched during $\mathrm{C}$-section. Estimated blood loss was 1.1L. Mother and baby were discharge after three days stay and the postpartum period was uneventful.

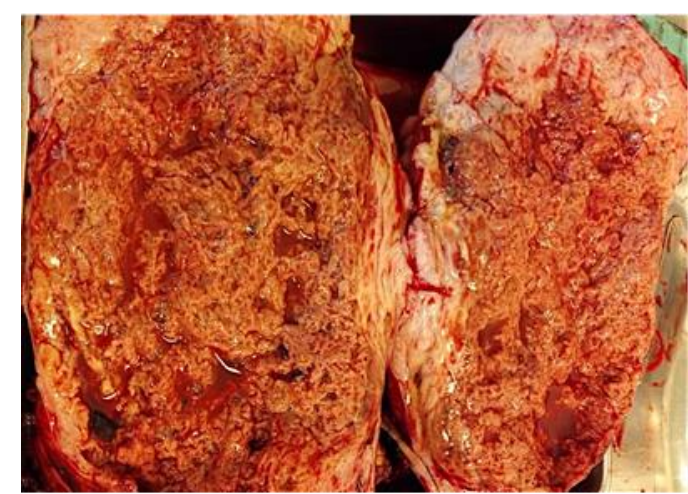

Fig.5. Cut section of fibroid shows dark brownish areas with suggestive of haemorrhage. 


\section{DISCUSSION}

Leiomyomas, the commonest tumour among woman and it usually affects woman of reproductive age, in which $60-80 \%$ occur in woman by age of 35 years [44]. Today, the incidence uterine fibroid in pregnancy is increasing due to delayed child bearing age. In this patient, she was diagnosed with uterine fibroid prior embarking on her pregnancy in 2014 after her miscarriage. She was counselled for surgical intervention i.e., laparotomy myomectomy in view of the size of fibroid however she opted for conservative management as she was asymptomatic and anxious about surgical intervention. Challenges of managing cases in our community are profound, and these range from poor health seeking behaviour, illiteracy, ignorance (lead to the feeling of fear for surgical intervention) and belief of traditional medicine in our community.

The possible effects of fibroids on pregnancy and the effects of pregnancy on fibroids are a common clinical concern. Although a lot of women with uterine fibroids carry the pregnancy to an end without adverse events, data provided in the literature suggests that uterine fibroid are associated with a high risk of spontaneous miscarriage, preterm labor, placental abruption, premature rupture of membranes (PROM), fetal malpresentation, labor dystocia, caesarean delivery, postpartum hemorrhage and hysterectomy [2]. Abdominal pain due to fibroid torsion and degeneration is a frequent complain during pregnancy [48]. Approximately 5-21\% of patient will require hospitalization for pain control. This usually occur in woman with large fibroid (size $>5 \mathrm{~cm}$ ) or posterior wall fibroid [49], perhaps result from torsion or partial obstruction of vessels supplying the pedunculated fibroid. Another reason of pain is red degeneration, occurring in $10 \%$ of pregnancy. It appears more often in pregnancy, usually during the first and beginning of the second trimester of pregnancy when the growth of myoma is more rapid. Clinically, patient with red degeneration of fibroid will present with acute onset of abdominal pain, with low grade fever, nausea and vomiting, localized tenderness over the fibroid, rebound tenderness, and leucocytosis, even if the clinical presentation is not acute [49]. Imaging modalities i.e., ultrasound and MRI can help to establish the diagnosis. On ultrasound, it shows change in echogenicity with internal cystic areas which may suggest red degeneration and infraction [50]. MRI may help to comfit the diagnosis and mapping of myoma prior to surgery. A diagnosis of red generation of the fibroid was made initially the presenting complain, clinical examination, supported by ultrasound and MRI findings is consistent to red degeneration. She was admitted and managed conservatively, along with packed cell transfusion as she was found to be anaemic. However conservative measures failed in her case. She was still in pain and haemoglobin count remain static despite with blood transfusion with vitals were consistent with hypovolemic shock (tachycardia), haemoglobin count static, yet no evidence of intraabdominal collection seen on radiological imaging. Bleeding from uterine leiomyoma can occur spontaneously especially in pregnancy and postpartum period, [39] and the bleeding is usually from ruptured enlarged veins over the surface of subserosal fibroid, resulting in hemoperitoneum but unlikely in this case there were no evidence of intraabdominal collection detected. It was difficult to come to the diagnosis of intra-tumour bleeding due to its rarity Intra-tumour massive bleeding is extremely rare. Only two case reported worldwide, both occurs during post-partum period, none during intrapartum period. Manatsawee et al. [45] reported a case of massive intra-tumour bleeding following delivery at 35 weeks via caesarean section for non-reassuring fetal status. Intraoperative noted presence of huge subserosal fibroid with $25 \mathrm{~cm}$ diameter at right side of uterus. Myomectomy was not done in view of risk of bleeding. However, on day 1 post operation, patient noted to be hypotensive and tachycardia. Ultrasonography of pelvis show no sign of intraperitoneal haemorrhage except that the size of fibroid increased drastically to $35 \mathrm{~cm}$ in diameter. Hysterectomy were performed and histologically noted massive blood collection in dilated vascular tree and infarct area of the mass which corresponds to the diagnosis of intra-leiomyoma haemorrhage. Koide et al. [46] reported a case of intraleoimyoma haemorrhage and was similar to that in manatsawee 's report in several aspects, including the timing of haemorrhage (just after delivery), huge subserous type of uterine fibroid. Similar to the case reported, this patient has a huge subserosal type of uterine fibroid however the timing of intra-tumour bleeding is different, this lady presented during antepartum period instead of postpartum period. It is postulated that large subserosal fibroid with pedicle or pedunculated fibroid is more prone to have intra-tumour bleeding due to impaired venous drainage of the large tumour through a small pedicle.

Management of uterine fibroid in pregnancy remain controversial and challenging. Pregnant women with painful fibroids may require hospitalization for pain management [11], [25]-[27]. For pain management in pregnancy, shortterm use of opioids in standard doses or a course of nonsteroidal anti-inflammatory drugs (NSAIDs) can be given. NSAID therapy should be limited to pregnancies less than 32 weeks of gestation because of the possibility of inducing premature closure of the ductus arteriosus, neonatal pulmonary hypertension, oligohydramnios, and fetal/neonatal platelet dysfunction [28]-[31]. If the NSAID is continued for $>48$ hours, weekly sonographic assessment for oligohydramnios and narrowing of the fetal ductus arteriosus should be performed. First trimester opioid use has been associated with an increased risk of congenital anomalies in some studies, but the data are weak and do not justify withholding these medications when needed to control pain. Case reports have described successful use of epidural analgesia for treatment of severe pain refractory to other therapies [34], [35]. This patient was referred to anaesthesia team for pain management. She was started on intravenous tramadol infusion (opioids) along with oral analgesics, paracetamol. Still, if conservative treatment fails to relieve the acute abdomen, surgical intervention may be required [32]. It is recommended that if symptoms persist after 72 hours of pharmacological therapy, surgical intervention must be considered [18], [36], [37]. In this case, it is justified for surgical intervention as she has persistent pain $>72$ hours.

Controversy persists among myomectomy being performed during pregnancy and at delivery, given the potential for harm (hemorrhage, uterine rupture, miscarriage, or preterm delivery), especially if an intramyometrial 
incision is required, [5], [15]-[24]. Analysis of cases reported in the literature suggests that myomectomy during pregnancy can be considered safe. The main complications of myomectomy during pregnancy includes miscarriage and haemorrhage. Mortality and morbidity are slightly higher in myomectomy in the gravid uterus as compared to non-gravid uterus as there is increased vascularity of the gravid uterus, thus it has greater risk of haemorrhage and the need for blood transfusion. Besides, the risk of abortion during myomectomy is also higher, ranging from $18 \%$ to $35 \%$ [42]. For this case, myomectomy was not done as it was a pedunculated type of fibroid, the stalk of fibroid was excised, and uterine wall was reconstructed using braided absorbable 1 suture (Ecosorb). Other fibroid was observed and not removed in view of massive bleeding. Measures to reduce bleeding during myomectomy in pregnant woman, i.e., injection of vasoconstrictor (vasopressin), use of foleys catheter as a tourniquet to compress uterine arteries at the base of broad ligament was no well-established. Some authors have used intraoperative vasopressin but the drawback may be its oxytocic-like effect.

The major concern was the reduction of fetal oxygenation if occlusion is prolonged. None of the case reports mention about prevention steps of haemorrhage when myomectomy is performed

Postoperatively, hydroxyprogesterone caproate is indicated for prophylaxis of abortion in high risk pregnancies because it compensates for hormone deficit, quiescent the myometrial activity and prevents premature labour [47]. Its use is strongly recommended. however, it was not prescribed in this case due to limited resources. Serial Ultrasonography during pregnancy is indicated in monitoring fetoplacental growth and evaluating size of the residual myoma following postoperatively, which was carried out in this particular case. It helped to evaluate growth of the foetus, placental localization, development of new myomas. Delivery should occur at tertiary centre with facilities for blood transfusion and caesarean section in view of increased risk of PPH and other associated complications. Elective caesarean section should be considered in woman with history of myomectomy, especially if the endometrial cavity was breached, the resultant defect was large, or a laparoscopic myomectomy was performed for intramural or submucosal fibroids [51]. This patient was schedule for an elective caesarean section at 39 weeks as to prevent uterine rupture. The true incidence of UR after myomectomy is difficult to assess: $1-3.7 \%$ of pregnancies has been reported in some studies, while in others it was estimated at $0.2 \%$ after abdominal myomectomy and $0.26 \%$ after laparoscopy [51]-[54].

\section{CONCLUSION}

Spontaneous intra-leiomyoma haemorrhage is extremely rare and should be suspected in patient presented with acute abdomen with sign of hypovolemic shock with anemia and subserosal/pedunculated type of fibroid. Rapid diagnosis and management are required as this can be a life-threatening condition.

\section{REFERENCES}

[1] Burton CA, Grimes DA, March CM. Surgical management of leiomyomata during pregnancy. Obstet Gynecol 1989;74:707-9.

[2] Phelan JP. Myomas and pregnancy. Obstet Gynecol Clin North Am 1995;22:801-5.

[3] Hasbargen U, Strauss A, Summerer-Moustaki M, et al. Myomectomy as a pregnancy-preserving option in the carefully selected patients. Fetal Diagn Ther 2002; 17:101-3

[4] Qidwai GI, Caughey AB, Jacoby AF. Obstetric outcomes in women with sonographically identified uterine leiomyomata. Obstet Gynecol 2006; $107: 376$

[5] Exacoustòs C, Rosati P. Ultrasound diagnosis of uterine myomas and complications in pregnancy. Obstet Gynecol 1993; 82:97.

[6] Strobelt N, Ghidini A, Cavallone M, et al. Natural history of uterine leiomyomas in pregnancy. J Ultrasound Med 1994; 13:399.

[7] Laughlin SK, Baird DD, Savitz DA, et al. Prevalence of uterine leiomyomas in the first trimester of pregnancy: an ultrasound-screening study. Obstet Gynecol 2009; 113:630.

[8] Stout MJ, Odibo AO, Graseck AS, et al. Leiomyomas at routine second-trimester ultrasound examination and adverse obstetric outcomes. Obstet Gynecol 2010; 116:1056.

[9] E. Danzer, W. Holzgreve, C. Batukan, P. Miny, S. Tercanli, and I. Hoesli, "Myomectomy during the first trimester associated with fetal limb anomalies and hydrocephalus in a twin pregnancy,"Prenatal Diagnosis, vol. 21, no. 10, pp. 848-851, 2001.

[10] Michalas SP, Oreopoulou FV, Papageorgiou JS. Myomectomy during pregnancy and cesarean section. Hum Reprod. 1995;10:1869-70.

[11] .Exacoustos C, Rosati P. Ultrasound diagnosis of uterine myomas and complications in pregnancy. Obstet Gynecol 1993;82:97-101.

[12] Lev-Toaff AS, Coleman BG, Arger PH, et al. Leiomyomas in pregnancy: sonographic study. Radiology 1987; 164:375.

[13] Aharoni A, Reiter A, Golan D, et al. Patterns of growth of uterine leiomyomas during pregnancy. A prospective longitudinal study. $\mathrm{Br} \mathrm{J}$ Obstet Gynaecol 1988; 95:510.

[14] Rosati P, Exacoustòs C, Mancuso S. Longitudinal evaluation of uterine myoma growth during pregnancy. A sonographic study. J Ultrasound Med 1992; 11:511.

[15] Katz VL, Dotters DJ, Droegemeuller W. Complications of uterine leiomyomas in pregnancy. Obstet Gynecol 1989; 73:593.

[16] De Carolis S, Fatigante G, Ferrazzani S, et al. Uterine myomectomy in pregnant women. Fetal Diagn Ther 2001; 16:116.

[17] Vergani P, Ghidini A, Strobelt N, et al. Do uterine leiomyomas influence pregnancy outcome? Am J Perinatol 1994; 11:356

[18] Buttram VC Jr, Reiter RC. Uterine leiomyomata: etiology, symptomatology, and management. Fertil Steril 1981; 36:433.

[19] Febo G, Tessarolo M, Leo L, et al. Surgical management of leiomyomata in pregnancy. Clin Exp Obstet Gynecol 1997; 24:76.

[20] Wittich AC, Salminen ER, Yancey MK, Markenson GR. Myomectomy during early pregnancy. Mil Med 2000; 165:162.

[21] Celik C, Acar A, Ciçek N, et al. Can myomectomy be performed during pregnancy? Gynecol Obstet Invest 2002; 53:79.

[22] Michalas SP, Oreopoulou FV, Papageorgiou JS. Myomectomy during pregnancy and caesarean section. Hum Reprod 1995; 10:1869.

[23] Glavind K, Palvio DH, Lauritsen JG. Uterine myoma in pregnancy. Acta Obstet Gynecol Scand 1990; 69:617.

[24] Mollica G, Pittini L, Minganti E, et al. Elective uterine myomectomy in pregnant women. Clin Exp Obstet Gynecol 1996; 23:168.

[25] Roberts WE, Fulp KS, Morrison JC, Martin JN Jr. The impact of leiomyomas on pregnancy. Aust N Z J Obstet Gynaecol 1999; 39:43.

[26] Phelan JP. Myomas and pregnancy. Obstet Gynecol Clin North Am $1995 ; 22: 801$.

[27] Hasan F, Arumugam K, Sivanesaratnam V. Uterine leiomyomata in pregnancy. Int J Gynaecol Obstet 1991; 34:45.

[28] Dildy GA 3rd, Moise KJ Jr, Smith LG Jr, et al. Indomethacin for the treatment of symptomatic leiomyoma uteri during pregnancy. Am J Perinatol 1992; 9:185.

[29] Niebyl JR, Witter FR. Neonatal outcome after indomethacin treatment for preterm labor. Am J Obstet Gynecol 1986; 155:747.

[30] Moise KJ Jr. Effect of advancing gestational age on the frequency of fetal ductal constriction in association with maternal indomethacin use. Am J Obstet Gynecol 1993; 168:1350.

[31] Vermillion ST, Scardo JA, Lashus AG, Wiles HB. The effect of indomethacin tocolysis on fetal ductus arteriosus constriction with advancing gestational age. Am J Obstet Gynecol 1997; 177:256.

[32] Vitale SG, Tropea A, Rossetti D, et al. Management of uterine leiomyomas in pregnancy: review of literature. Updates Surg 2013; 65:179. 
[33] Tower AM, Cronin B. Myomectomy after a vaginal delivery to treat postpartum hemorrhage resulting from an intracavitary leiomyoma. Obstet Gynecol 2015; 125:1110.

[34] Treissman DA, Bate JT, Randall PT. Epidural use of morphine in managing the pain of carneous degeneration of a uterine leiomyoma during pregnancy. Can Med Assoc J 1982; 126:505.

[35] Kwon SY, Lee G, Kim YS. Management of severely painful uterine leiomyoma in a pregnant woman with epidural block using a subcutaneous injection port. Acta Obstet Gynecol Scand 2014; 93:839.

[36] D. E. Lolis, S. N. Kalantaridou, G. Makrydimas et al., "Successful myomectomy during pregnancy," Human Reproduction, vol. 18, no. 8, pp. 1699-1702, 2003.

[37] N. Bhatla, B. B. Dash, A. Kriplani, and N. Agarwal, "Myomectomy during pregnancy: a feasible option," Journal of Obstetrics and Gynaecology Research, vol. 35, no. 1, pp. 173-175, 2009.

[38] G. Mollica, L. Pittini, E. Minganti, G. Perri, and F. Pansini, "Elective uterine myomectomy in pregnant women," Clinical and Experimental Obstetrics and Gynecology, vol. 23, no. 3, pp. 168-172, 1996.

[39] Danikas D, Theodorou SJ, Kotrotsios J, Sills C, Cordero PE. Hemoperitoneum from spontaneous bleeding of a uterine leiomyoma: A case report. Am Surg 1999; 65: 1180-1182.

[40] V. Lozza, A. Pieralli, S. Corioni, M. Longinotti, and C. Penna, "Multiple laparotomic myomectomy during pregnancy: a case report," Archives of Gynecology and Obstetrics, vol. 284, no. 3, pp. 613-616, 2011.

[41] Salih H.A.M, Sarsam RI, Abed MF, et al. Uterine fibroid causing intestinal obstruction: report of a case. J Young Pharmacists. 2015;7(4):399-402.

[42] Domenici L, Donato VDI, Gasparri ML, et al. Laparotomic myoomectomy in the 16th week of pregnancy: a case report. Case reports in Obst and Gynecology. Hindawi Publishing Corporation. 2014:154347:1-5.

[43] Glavind K, Palvio DH, Lauritsen JG. Uterine myoma in pregnancy. Acta obstetrician et gynecologica Scandinavica. 1990 Jan 1;69(78):617-9.

[44] Day Baird D, Dunson DB, Hill MC, et al. High cumulative incidence of uterine leiomy- oma in black and white women: Ultrasound evidence. American Journal of Obstetrics and Gynecology. 2003;188:100-107.

[45] Manopunya, Manatsawee \& Tongprasert, Fuanglada \& Sukpan, Kornkanok \& Tongsong, Theera. (2012). Intra-leiomyoma massive hemorrhage after delivery. The journal of obstetrics and gynaecology research. 39. 10.1111/j.1447-0756.2012.01932.x.

[46] Koide, K., Sekizawa, A., Nakamura, M., Matsuoka, R. and Okai, T. (2009), Hypovolemic shock due to massive edema of a pedunculated uterine myoma after delivery. Journal of Obstetrics and Gynaecology Research, 35: 794-796.

[47] Frederick J. Mccann. Pregnancy complicated by a fibroid tumour showing "Red Degeneration." Proc R Soc Med.t908 ;1 (ObstetGynaecol Sect): 315-320.

[48] Milazzo, Giusi \& Catalano, Angelica \& Badia, Valentina \& Mallozzi, Maddalena \& Caserta, Donatella. (2017). Myoma and myomectomy: Poor evidence concern in pregnancy. Journal of Obstetrics and Gynaecology Research.

[49] Deveer M, Deveer R, Engin-Ustun Y et al. Comparison of preg- nancy outcomes in different localizations of uterine fibroids. Clin Exp Obstet Gyneco 2012; 39: 516-518.

[50] CookH,EzzaliM,SegarsJH,McCarthyD.Theimpactofuter- ine leiomyomas on reproductive outcomes. Minerva Ginecol 2010; 62: 225-236.

[51] Parker WH. Laparoscopic myomectomy and abdominal myomectomy. Clin Obstet Gynecol 2006; 49: 789-797.

[52] Parker WH, Einarsson J, Istre O, Dubuisson JB. Risk factor for uterine rupture after laparoscopic myomectomy. J Minim Inva- sive Gynecol 2010; 17: 551-554.

[53] Zhang Y, Hua K. Patients' age, myoma size, myoma location and interval between myomectomy and pregnancy may influ- ence the pregnancy rate and live birth rate after myomectomy. J Laparoendosc Adv Surg Tech A 2014; 24: 95-99.

[54] Claeys J, Hellendoorn I, Hamerlynck T, Bosteels J, Weyers S. The risk of uterine rupture after myomectomy: A systematic review of the literature and metanalysis. Gynecol Surg 2014; 11: 197-206. 